\title{
openheart Impact of ultrasound contrast agent during transoesophageal echocardiography on the sizing of the left atrial appendage
}

\author{
Henning Ebelt (D), Sarah Goetze, Anja Weida, Alexandra Offhaus
}

To cite: Ebelt $\mathrm{H}$, Goetze $\mathrm{S}$, Weida A, et al. Impact of ultrasound contrast agent during transoesophageal echocardiography on the sizing of the left atrial appendage. Open Heart 2021;8:e001403. doi:10.1136/ openhrt-2020-001403

Received 30 July 2020 Revised 19 December 2020 Accepted 9 March 2021

\section{ABSTRACT}

Introduction Interventional closure of the left atrial appendage closure (LAAC) has been established as an alternative treatment in patients with atrial fibrillation (AF) and an increased risk of stroke. So far it is unknown whether the use of ultrasound contrast agent (UCA) would influence the correct sizing of the LAA and thereby have an impact on device selection during interventional LAAC. Methods Between January 2017 and April 2018, 223 transoesophageal echocardiography (TOE) examinations were prospectively performed in adult patients with nonvalvular AF (Impact of the use of ultrasound contrast agent on the detection of thrombi in the left atrial appendage during transesophageal echocardiography (CONDOR) study). LAA was examined both with and without the use of UCA. The following measurements were taken at $0^{\circ}$, $45^{\circ}, 90^{\circ}$ and $135^{\circ}$ : diameter of LAA ostium, maximal depth of the LAA, maximal available depth of the LAA orthogonal to the ostial plane and area of the LAA.

Results The use of UCA had no relevant influence on the size determination of the LAA. Additionally, Bland-Altman blots demonstrate a high degree of correlation between the measurements with and without UCA with no evidence for a systematic effect arising from the use of UCA. When comparing the measurements of two independent investigators, the use of UCA rather leads to a higher variability than to an improved precision.

Discussion Despite the fact that the use of UCA during TOE leads to an improved rule out of thrombi, our study shows that there is no advantageous effect of UCA on the size determination of the LAA and should therefore not be used for this purpose.

\section{INTRODUCTION}

(C) Author(s) (or their employer(s)) 2021. Re-use permitted under CC BY-NC. No commercial re-use. See rights and permissions. Published by BMJ.

Department of Medicine II, Catholic Hospital, Sankt Johann Nepomuk, Erfurt, Thüringen, Germany

Correspondence to Dr Henning Ebelt; henningebelt@gmail.com
Atrial fibrillation (AF) is associated with an increased risk of intracardiac thrombus formation and subsequent stroke and systemic embolism. In at least $90 \%$ of cases, the underlying thrombi are originating from the left atrial appendage (LAA). ${ }^{12}$ Within the last years, interventional LAA closure (LAAC) has been established as an alternative treatment in patients with $\mathrm{AF}$ and an increased risk of stroke especially if contraindications regarding the use of oral anticoagulation are

\section{Key questions}

What is already known about this subject?

- The interventional occlusion of the left atrial appendage closure is nowadays an alternative treatment strategy for patients with atrial fibrillation (AF) and a high thromboembolic risk if oral anticoagulation is considered contraindicated. Correct size determination of the left atrial appendage (LAA) is of crucial importance in these patients. In previous studies, it has been reported that the use of ultrasound contrast agent (UCA) improves the diagnostic yield of transoesophageal echocardiography (TOE) regarding the detection of thrombi in patients with AF. However, no information is available whether the use of UCA also improves the correct sizing of the LAA.

What does this study add?

- This study shows that the routine use of UCA in patients with AF does not have an impact on size determination of the LAA. Surprisingly, the use of UCA rather leads to a higher variability than to an improved precision.

How might this impact on clinical practice?

- This study shows that during TOE there is no advantageous effect of UCA on the size determination of the LAA and that UCA therefore should not be used for this purpose.

existing. ${ }^{3}$ For an optimal procedural result of LAAC, a detailed knowledge of the anatomy and size of the LAA is of crucial importance. In clinical practice, transoesophageal echocardiography (TOE) is the standard imaging modality to evaluate the LAA which nowadays is complemented by CT scan, both to rule out LAA thrombi as well as to select a suitable device for LAAC. We have recently shown in a prospective study (CONDOR) that the use of ultrasound contrast agent (UCA) improves the rule out of LAA thrombi in patients with $\mathrm{AF}$ and has a significant impact on the management of these patients if they are scheduled for an interventional procedure. ${ }^{4}$ 
However, so far it has not been reported whether UCA would also have an impact on the determination of the size of the LAA. As UCA can lead to an improved delineation of the endocardial borders, it seems possible that this might translate into effects on the size determination of the LAA during TOE and thereby have an impact especially on device selection during interventional LAAC.

\section{METHODS}

The data presented here were acquired as a part of the prospective CONDOR Study ('Impact of the use of ultrasound contrast agent on the detection of thrombi in the left atrial appendage during transoesophageal echocardiography', German Registry of Clinical Trials, DRKS00011716) that has been described before. ${ }^{4}$ Between January 2017 and April 2018, 223 TOE examinations were prospectively performed in adult patients with non-valvular AF. All TOEs were performed according to the clinical standards using a General Electric Vivid E9 (GE, Boston, Massachusetts, USA) equipped with a 3D probe (model 6T), all images were taken using harmonic imaging. Patients received local anaesthesia of the throat with $2 \%$ xylocaine pump spray (Aspen Germany $\mathrm{GmbH}$, Munich, Germany) and afterwards 2-5 mg midazolam intravenous (Ratiopharm, Ulm, Germany). LAA was examined both without the use of UCA at $0^{\circ}, 45^{\circ}, 90^{\circ}$ and $135^{\circ}$ at imaging settings used in clinical routine and again after intravenous injection of $1.0 \mathrm{~mL}$ of the UCA Sonovue (Bracco International B.V., Amsterdam, The Netherlands). The settings of the echo machine were adjusted for the use of UCA by reducing acoustic power to $-32 \mathrm{~dB} /-28 \mathrm{~dB}$ resulting in a mechanical index of $0.04-0.1$. If image quality after administration of UCA was not satisfying, a second bolus of $1.0 \mathrm{~mL}$ Sonovue could be given. For quantification of the LAA, all TOE loops were stored and analysed by an independent investigator. The following measurements were taken at $0^{\circ}, 45^{\circ}, 90^{\circ}$ and $135^{\circ}$ : diameter of LAA ostium, maximal depth of the LAA, maximal available depth of the LAA orthogonal to the ostial plane and area of the LAA.

\section{Statistical analysis}

Statistical data analysis was performed using SPSS Statistics (V.26, SPSS). Differences in frequency of nominally scaled parameters were compared by means of Pearson's $\chi^{2}$ test. Metric variables are expressed as mean $\pm \mathrm{SD}$ and were compared with Student's t-test.

\section{RESULTS}

Patient characteristics are given in table 1 (see also Ebelt $e t$ al). ${ }^{4}$ The dimensions of the LAA as determined with and without the administration of UCA are given in table 2. No relevant differences were seen between the groups for the parameters that were analysed. Additionally, BlandAltman blots for the quantification of the LAA ostium are given in figure 1 demonstrating a high degree of correlation between the measurements with and without UCA.

\begin{tabular}{ll}
\hline \multicolumn{2}{l}{ Table 1 Characteristics of study patients $(\mathrm{N}=223)$} \\
\hline Parameter & Value \\
\hline Age (years) & $71.3 \pm 9.9$ \\
\hline Gender, male & $122(54.7 \%)$ \\
LV-EF $(\%)$ & $51.7 \pm 14.0$ \\
\hline Type of atrial fibrillation & \\
$\quad$ Paroxysmal & $71(31.8 \%)$ \\
\hline Persistent & $123(55.1 \%)$ \\
\hline Permanent & $29(13.0 \%)$ \\
Hypertension & $200(89.7 \%)$ \\
\hline Diabetes & $85(38.1 \%)$ \\
\hline Previous stroke & $31(13.9 \%)$ \\
\hline
\end{tabular}

See also Ebelt et al. ${ }^{4}$

$\mathrm{LV}-\mathrm{EF}$, left ventricular ejection fraction.

However, there is no evidence of a systematic sizing effect arising from the use of UCA.

In order to determine whether the use of UCA would lead to a higher precision of the quantifications, all

Table 2 Dimensions of the LAA ostium determined by TOE with and without UCA in different standard views $(\mathrm{N}=223)$

\begin{tabular}{|c|c|c|c|}
\hline & Without UCA & With UCA & $P$ value \\
\hline \multicolumn{4}{|l|}{$0^{\circ}$} \\
\hline Diameter (mm) & $19.4 \pm 5.2$ & $20.2 \pm 4.8$ & 0.056 \\
\hline Max. depth (mm) & $25.1 \pm 7.1$ & $25.0 \pm 5.9$ & 0.546 \\
\hline $\begin{array}{l}\text { Orthogonal depth } \\
(\mathrm{mm})\end{array}$ & $21.4 \pm 5.8$ & $21.3 \pm 5.5$ & 0.603 \\
\hline Area $\left(\mathrm{mm}^{2}\right)$ & $385.3 \pm 142.3$ & $391.7 \pm 126.1$ & 0.772 \\
\hline \multicolumn{4}{|l|}{$45^{\circ}$} \\
\hline Diameter (mm) & $19.0 \pm 4.2$ & $18.7 \pm 3.9$ & 0.352 \\
\hline Max. depth (mm) & $23.9 \pm 5.5$ & $24.3 \pm 5.3$ & 0.359 \\
\hline $\begin{array}{l}\text { Orthogonal depth } \\
(\mathrm{mm})\end{array}$ & $19.4 \pm 4.8$ & $19.8 \pm 4.6$ & 0.257 \\
\hline Area $\left(\mathrm{mm}^{2}\right)$ & $358.3 \pm 118.9$ & $374.3 \pm 109.7$ & 0.025 \\
\hline \multicolumn{4}{|l|}{$90^{\circ}$} \\
\hline Diameter (mm) & $18.8 \pm 4.3$ & $19.0 \pm 4.1$ & 0.378 \\
\hline Max. depth (mm) & $25.5 \pm 6.0$ & $24.4 \pm 5.1$ & 0.010 \\
\hline $\begin{array}{l}\text { Orthogonal depth } \\
(\mathrm{mm})\end{array}$ & $20.3 \pm 5.6$ & $19.9 \pm 4.8$ & 0.309 \\
\hline Area $\left(\mathrm{mm}^{2}\right)$ & $391.2 \pm 121.8$ & $389.5 \pm 108.3$ & 0.879 \\
\hline \multicolumn{4}{|l|}{$135^{\circ}$} \\
\hline Diameter (mm) & $19.3 \pm 5.5$ & $19.1 \pm 5.0$ & 0.700 \\
\hline Max. depth (mm) & $22.5 \pm 5.9$ & $22.7 \pm 5.6$ & 0.650 \\
\hline $\begin{array}{l}\text { Orthogonal depth } \\
(\mathrm{mm})\end{array}$ & $20.9 \pm 5.9$ & $21.1 \pm 5.8$ & 0.602 \\
\hline Area $\left(\mathrm{mm}^{2}\right)$ & $364.2 \pm 113.3$ & $379.1 \pm 112.4$ & 0.039 \\
\hline
\end{tabular}

LAA, left atrial appendage closure; $P$, level of significance (paired ttest); TOE, transoesophageal echocardiography; UCA, ultrasound contrast agent. 


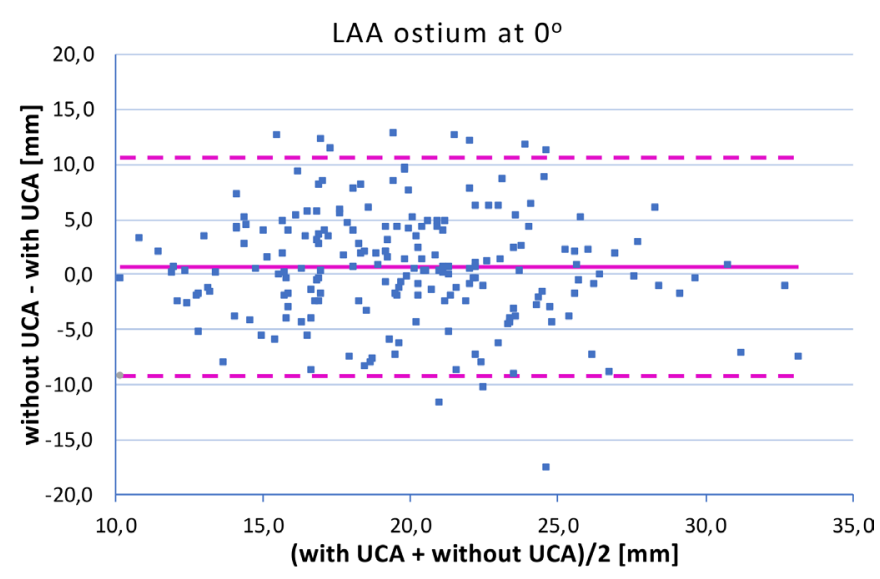

LAA ostium at $45^{\circ}$

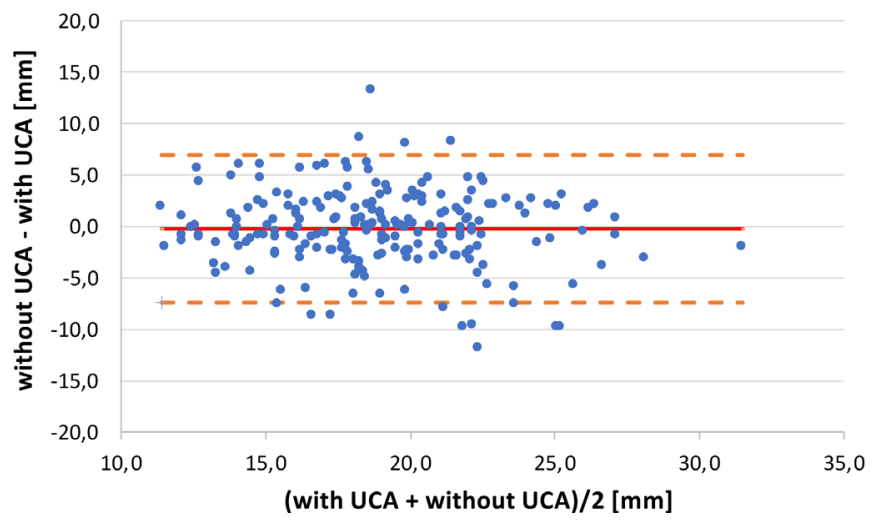

Figure 1 Bland-Altman blots for the quantification of the LAA ostium with and without the use of ultrasound contrast agent. LAA, left atrial appendage; UCA, ultrasound contrast agent.

measurements of the LAA ostium were repeated by a second investigator (table 3 ). When comparing the differences it turns out that the use of UCA rather leads to a higher variability between the two investigators than to an improved precision. This finding could be observed in three of the four standard views $\left(45^{\circ}, 90^{\circ}, 135^{\circ}\right)$.

It is known that in patients with a bilobar LAA morphology, both the diagnosis of LAA thrombi as well as the interventional LAAC might turn out to be challenging. ${ }^{56}$ Therefore, we especially determined whether the use of UCA is helpful in these cases. In our study, a bilobar LAA was found in 86 out of the 223 examinations. However, also in these cases, the application of UCA did not result in a better precision of the measurements (table 3).

\section{DISCUSSION}

Correct sizing of the LAA is of crucial importance during LAAC. To date, the predominant imaging modality to guide LAAC is TOE, although other imaging modalities like intracardiac echocardiography can be considered as an alternative leading to comparable clinical results. ${ }^{7}$
Table 3 Precision of size determination of the LAA ostium depending on the use of UCA in the total cohort of patients and in patients with bilobar LAA morphology, respectively

\begin{tabular}{|c|c|c|c|}
\hline TOE view & $\begin{array}{l}\text { Measured } \\
\text { difference of } \\
\text { LAA ostium } \\
\text { without UCA } \\
(\mathrm{mm})\end{array}$ & $\begin{array}{l}\text { Measured } \\
\text { difference of } \\
\text { LAA ostium } \\
\text { with UCA } \\
(\mathrm{mm})\end{array}$ & $P$ value \\
\hline \multicolumn{4}{|l|}{ All patients $(\mathrm{N}=223)$} \\
\hline All views ( $\mathrm{N}=715)$ & $0.97 \pm 4.22$ & $1.83 \pm 3.81$ & $<0.001$ \\
\hline $0^{\circ}(\mathrm{N}=144)$ & $1.35 \pm 5.01$ & $1.42 \pm 4.48$ & 0.871 \\
\hline $45^{\circ}(\mathrm{N}=200)$ & $0.42 \pm 3.62$ & $1.54 \pm 3.29$ & $<0.001$ \\
\hline $90^{\circ}(\mathrm{N}=199)$ & $1.04 \pm 3.87$ & $1.89 \pm 3.45$ & 0.002 \\
\hline $135^{\circ}(\mathrm{N}=172)$ & $1.22 \pm 4.53$ & $2.42 \pm 4.08$ & 0.004 \\
\hline \multicolumn{4}{|c|}{ Patients with bilobar LAA $(\mathrm{N}=86)$} \\
\hline All views $(\mathrm{N}=305)$ & $0.96 \pm 4.23$ & $1.54 \pm 4.05$ & 0.038 \\
\hline $0^{\circ}(\mathrm{N}=63)$ & $0.90 \pm 4.78$ & $0.89 \pm 4.78$ & 0.989 \\
\hline $45^{\circ}(\mathrm{N}=84)$ & $0.57 \pm 3.71$ & $1.27 \pm 3.35$ & 0.093 \\
\hline $90^{\circ}(\mathrm{N}=83)$ & $1.15 \pm 4.16$ & $1.78 \pm 3.61$ & 0.133 \\
\hline $135^{\circ}(\mathrm{N}=75)$ & $1.33 \pm 4.40$ & $2.11 \pm 4.52$ & 0.242 \\
\hline
\end{tabular}

Shown are the differences of the size of the LAA ostium as measured by two independent operators with or without UCA. LAA, left atrial appendage; TOE, transoesophageal echocardiography; UCA, ultrasound contrast agent.

We and others have shown previously that the use of UCA during TOE can improve the rule out of thrombi in patients with $\mathrm{AF}^{489}$ which in our study led to a $38 \%$ reduction of the inadequate postponing of interventional procedures. ${ }^{4}$ However, so far there are no reports describing whether the use of UCA would also have an impact on the size determination of the LAA and whether UCA would perhaps increase the precision of LAA sizing in TOE.

It a well-known fact that different imaging modalities often lead to systematic differences in the size determination of cardiac structures. For instance, sizing of the aortic anulus will systematically yield larger values if CT scan is used instead of echocardiography (review in van Gils et al).$^{10}$ Likewise, it has been shown that the size of the LAA orifice is systematically underestimated in 2D TOE in comparison to CT scan or 3D TOE, respectively. ${ }^{11}$ One of our hypotheses for the study presented here was that a better delineation of the endocardial borders arising from the routine use of UCA during TOE might both have an impact on the size determination of the LAA as well as improve the precision of the measurements indicated by a reduced interobserver variability, respectively. However, after a detailed analysis of 223 prospective TOE examinations that were performed to evaluate the LAA in patients with AF, it turned out that UCA neither had an impact on the sizing of the LAA nor led to an increased precision of the measurements. On the contrary, interobserver variability was found to be significantly increased when UCA was applied. 
It has to be mentioned that in our study, the image quality of the LAA was graded as poor in 15 out of 223 examinations $(6.7 \%)$. In these examinations, the majority of measurements could not be taken so that the effect of UCA in these cases is difficult to judge.

Taken together, our study shows that although the use of UCA during TOE leads to an improved rule out of thrombi there is no advantageous effect of the UCA on the size determination of the LAA and should therefore not be used for this purpose.

\section{Limitations}

Our study has a number of limitations. Although the number of TOE examinations was considerably high (223 examinations), it was not possible to obtain images of all standards views for all individual patients. Additionally, all quantifications were performed in 2D but not in 3D datasets. In our study, the UCA had been administered as a single intravenous bolus according to the manufacturer's instructions; however, it might have been of advantage to use an infusion pump to reduce near field shielding. Due to the study design, no other imaging modalities such as CT scan could be included in the analyses.

Contributors HE: planning and conduct of the study, writing of the manuscript and responsible for the overall content. SG: planning and conduct of the study, data acquisition and manuscript revision. AW: data acquisition and manuscript revision. $\mathrm{AO}$ : conduct of the study, manuscript revision and data acquisition.

Funding This study was partially supported by a grant from Boston Scientific (Investigator Sponsored Research).

Competing interests HE has received honoraria for lectures from Bayer, Novartis, Pfizer, Boehringer Ingelheim and Boston Scientific.

Patient consent for publication Not required.

Ethics approval The study complies with the Declaration of Helsinki. Any necessary ethics committee approval was secured for the study reported. The research protocol has been approved by the Ethics Committee of the Medical Association of Thuringia and informed consent has been obtained from all subjects.

Provenance and peer review Not commissioned; externally peer reviewed.

Data availability statement Data are available upon reasonable request.
Open access This is an open access article distributed in accordance with the Creative Commons Attribution Non Commercial (CC BY-NC 4.0) license, which permits others to distribute, remix, adapt, build upon this work non-commercially, and license their derivative works on different terms, provided the original work is properly cited, appropriate credit is given, any changes made indicated, and the use is non-commercial. See: http://creativecommons.org/licenses/by-nc/4.0/.

ORCID iD

Henning Ebelt http://orcid.org/0000-0003-2465-1812

\section{REFERENCES}

1 Klein AL, Grimm RA, Murray RD, et al. Use of transesophageal echocardiography to guide cardioversion in patients with atrial fibrillation. N Engl J Med 2001;344:1411-20.

2 Cresti A, García-Fernández MA, Sievert H, et al. Prevalence of extra-appendage thrombosis in non-valvular atrial fibrillation and atrial flutter in patients undergoing cardioversion: a large transoesophageal echo study. Eurolntervention 2019;15:e225-30.

3 Kirchhof P, Benussi S, Kotecha D, et al. 2016 ESC guidelines for the management of atrial fibrillation developed in collaboration with EACTS. Rev Esp Cardiol 2017;70:50.

4 Ebelt $\mathrm{H}$, Offhaus A, Wiora M, et al. Impact of ultrasound contrast agent on the detection of thrombi during transoesophageal echocardiography. Open Heart 2019;6:e001024.

5 Noutsias M, Melnyk H, Ali M, et al. Dual device closure of a bilobar left atrial appendage with a plug (Watchman 2.5 $5^{\mathrm{TM}} 30 \mathrm{~mm}$ ) and a pacifier (Amulet ${ }^{\mathrm{TM}} 20 \mathrm{~mm}$ ) device. Hellenic J Cardiol 2020;137.

6 Mizuguchi KA, Burch TM, Bulwer BE, et al. Thrombus or bilobar left atrial appendage? diagnosis by real-time three-dimensional transesophageal echocardiography. Anesth Analg 2009;108:70-2.

7 Ribeiro JM, Teixeira R, Puga L, et al. Comparison of intracardiac and transoesophageal echocardiography for guidance of percutaneous left atrial appendage occlusion: a meta-analysis. Echocardiography 2019;36:1330-7.

8 Jung PH, Mueller M, Schuhmann C, et al. Contrast enhanced transesophageal echocardiography in patients with atrial fibrillation referred to electrical cardioversion improves atrial thrombus detection and may reduce associated thromboembolic events. Cardiovasc Ultrasound 2013;11:1.

9 Bernier M, Abdelmoneim SS, Stuart Moir W, et al. CUTE-CV: a prospective study of enhanced left atrial appendage visualization with microbubble contrast agent use during transesophageal echocardiography guided cardioversion. Echocardiography 2013;30:n/a-7.

10 van Gils L, Tchetche D, Latib A, et al. TAVI with current CEmarked devices: strategies for optimal sizing and valve delivery. Eurolntervention 2016;12:Y22-7.

11 Nucifora G, Faletra FF, Regoli F, et al. Evaluation of the left atrial appendage with real-time 3-dimensional transesophageal echocardiography: implications for catheter-based left atrial appendage closure. Circ Cardiovasc Imaging 2011;4:514-23. 